\title{
Globally customer oriented
}

"We are wherever our customers are." This MANN+HUMMEL principle stretches right back to the 1950s.

MANN+HUMMEL made its first steps in the direction of internationalization with its production facilities in Argentina and Brazil - and to this day continues to strive for global growth.

MANN+HUMMEL follows its customers' lead and produces its products where they are needed. With this strategy, the company consistently adapts to global developments: the automobile market is in a long-term growth phase. Demand is growing annually by approximately three percent. In particular, in Asian countries like China and India as well as in North America and Russia the growth push is unstoppable.
This applies equally for the original equipment area and for the spare parts business. The global market volume in the automotive supplier industry will increase, according to forecasts by market researchers from one billion euro in 2013 to up to two billion euro in 2020.

MANN+HUMMEL wants to participate in this growth and has, since as far back as the 1990s, defined the globalization of development, production, and sales as its top priority. The acquisition of companies in related sectors, in particular the takeover completed in 2016 of the global filtration business of the Affinia Group, is as important in this process as the establishment of its own subsidiaries and the creation of joint ventures.
Such a far-reaching internationalization strategy must be carefully prepared. Personnel and financial changes or cultural differences are challenges that a globally active company must face. MANN+HUMMEL meets this risks with self-confidence - and success: at the moment, over 20,000 employees work in the company at more than 60 locations. In this global network, the German location is and remains the development engine for innovations, for example with the technology center at the Ludwigsburg headquarters which opened in July 2016 and with the world's largest filter factory in the Bavarian city of Marklkofen.

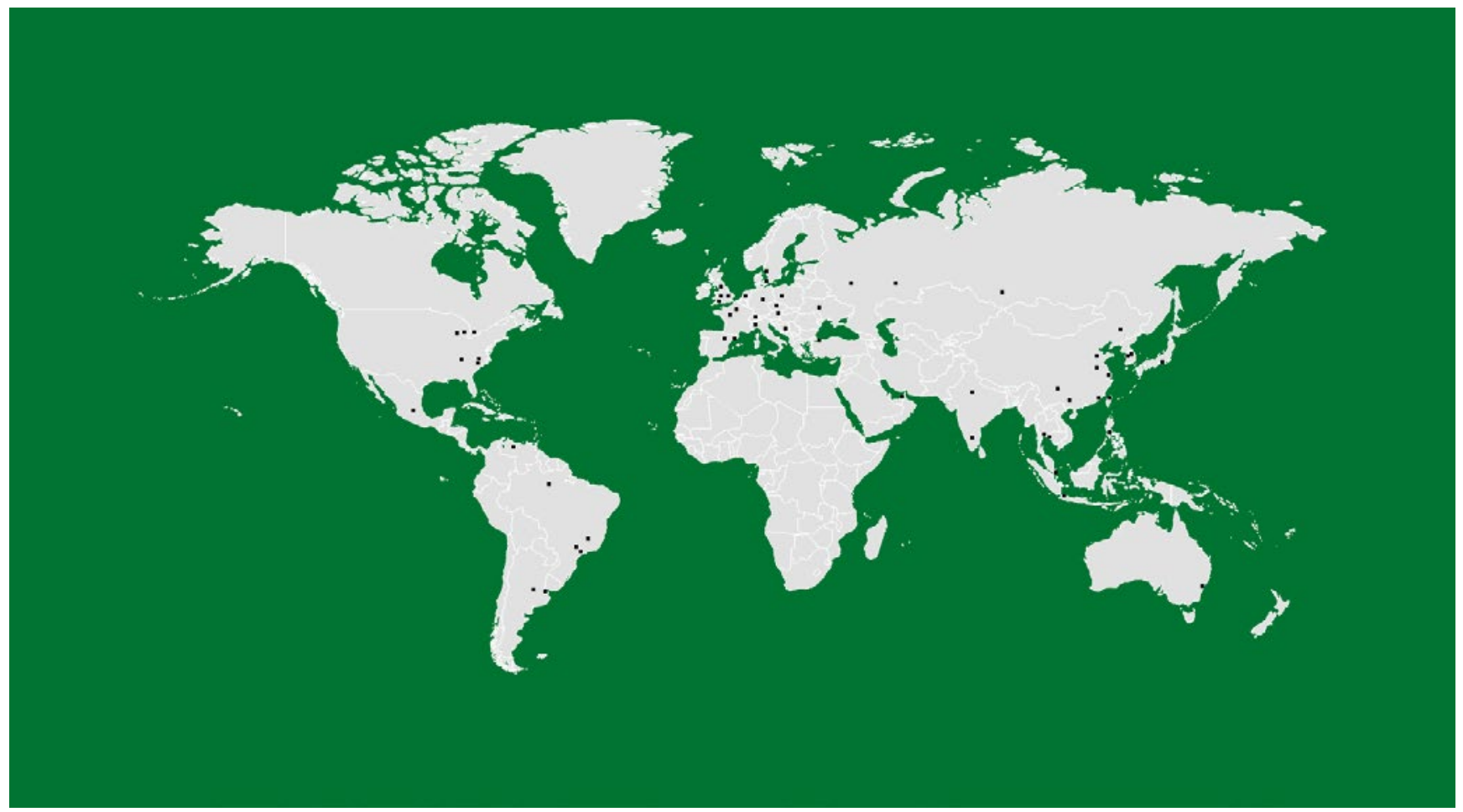

FIGURE 1 MANN+HUMMEL locations are spread around the entire world (@ MANN+HUMMEL) 